\title{
A Case Study of Teaching Large Class Based on Easyclass Platform
}

\author{
Tan Baihong \\ Economic \& Management College, \\ Tianjin University of Science \& Technology, \\ Tianjin, China \\ e-mail: tanbaihong@tust.edu.cn
}

\author{
Daji Yu \\ Department of Network Technology, \\ Tianjin Electronic Information College, \\ Tianjin, China \\ e-mail: yudaji@126.com
}

\begin{abstract}
In the context of the current widespread large classes teaching in universities of China, an in-depth analysis was carried out from the perspective of knowledge dissemination within internal organization and Collaborative Knowledge Building, the existing teaching pattern was generalized as a pyramid-shaped model, which is not conducive to the spread of knowledge in large classes. In order to achieve good teaching effects, the traditional communication way should be changed. An open communication network platform should be employed to promote knowledge dissemination within large classes. Easyclass was used to facilitate teaching for a large class over 150 registered students in Database Application. An outline of the teaching mode was given thoroughly in this paper.
\end{abstract}

Keywords-knowledge dissemination; large class; class management; Easyclass

\section{INTRODUCTION}

Currently, most of China's colleges and universities are using small classes (fewer than 30 students) for specialty courses, and large classes (larger than 30 students) for common courses. There is a big difference between the elite universities in the United States and China, according to statistics provided by USNews as shown in Table 1, in 2011 the proportion of classes fewer than 20 students was over $75 \%$ among top 10 comprehensive universities in USA. While in China, take Fudan University who did best in teaching in small classes as an example, 2317 courses for undergraduate in Fudan University was given in the second semester of school year from 2011 to 2012. However, the courses arranged in small classes $(<=30)$ of the curriculum was only 1108 , only about $47.82 \%$ of all undergraduate courses (data from the 2011-2012 school year, Fudan University teaching task file). It's far below the level of comprehensive universities in USA.

IN China, most common courses are usually not purely knowledge-based, and they are mainly focus on enlightment wisdom and thoughts, cultural inheritance, etc. They are usually given in large class. The teaching emphasis is not what students should remember, but is to guide students to think [1]. However there are some issues such as poor teacher-student interaction, hard classroom management etc. for courses taught in large class. With present situation, an in-depth analysis was carried out from the perspective of knowledge dissemination within internal organization and Collaborative Knowledge Building to achieve better teaching effects. This paper further combined a case study with the actual curriculum teaching of database application, employing Easyclass as an effective course management platform to carry out teaching in large class.

TABLE I 2011 Top 10 universities in USA with classes Fewer than 20 students

\begin{tabular}{ccc}
\hline National University (state) & $\begin{array}{c}\text { Undergraduate } \\
\text { enrolment }\end{array}$ & $\begin{array}{c}\text { Classes with fewer } \\
\text { than 20 students }\end{array}$ \\
\hline New School (NY) & 6,970 & $92.1 \%$ \\
Immaculata University (PA) & 3,223 & $81.6 \%$ \\
Edgewood College (WI) & 1,941 & $81.3 \%$ \\
Cardinal Stritch University (WI) & 2,984 & $80.7 \%$ \\
Columbia University (NY) & 5,888 & $79.7 \%$ \\
Harvard University (MA) & 6,641 & $79.5 \%$ \\
University of Chicago & 5,238 & $77.8 \%$ \\
Nova Southeastern University & 6,174 & $76.1 \%$ \\
(FL) & 5,310 & $75.8 \%$ \\
Yale University (CT) & 8,443 & $75.0 \%$ \\
\hline Northwestern University (IL) &
\end{tabular}

\section{ANALYSIS FROM PERSPECTIVE OF KNOWLEDGE DISSEMINATION WITHIN LARGE CLASSES}

Knowledge dissemination theory holds that people play most important role in the process of knowledge dissemination, from the inception to completion People are the main carriers of knowledge, at the same time they are also the recipient of knowledge disseminations [2,3]. Effective teaching is actually the process effective dissemination of knowledge in groups consisting of teachers and students. The current teaching mode of courses in large classes is still teacher-centered, while students accept teaching content passively. A lot of information in form of PPT slides is presented to the students in classroom, which is often a passive acceptance status for students. By this teaching mode teacher is in the highest position as course organizers and managers, those students who concentrate on learning are below the teacher, they can grasp most of the knowledge and a few of them can further transfer the knowledge to their surrounding students, however for a rather large amount of students who are easily become dependent individuals in learning process, lack communication with teachers and classmates, grasp limited knowledge in learning process. Thus the knowledge dissemination model appears like a pyramid-shaped structure shown in Fig 1. 


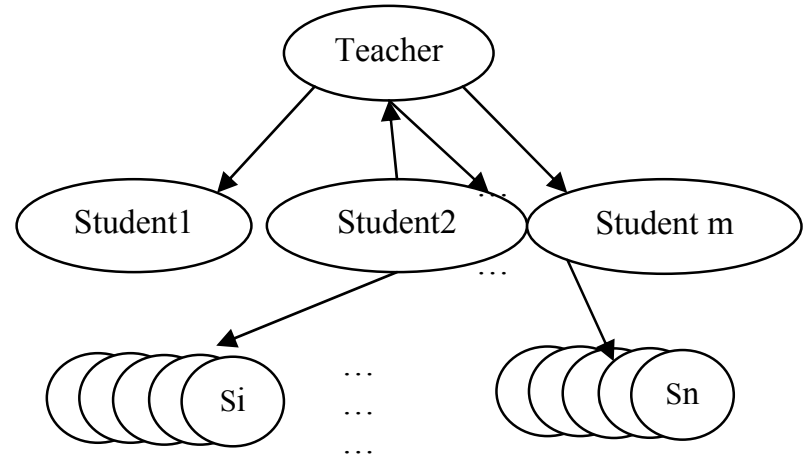

Fig. 1 Knowledge dissemination in large class

The structure in Fig 1 shows that only few two-way communications links exist between the teacher and active individual students who absorb knowledge better, and much fewer can further spread to other students, which is not conducive to the effective knowledge dissemination.

The teaching process of a course in large classes can be seen as a relatively closed system, for there are few personnel changes during teaching process; for students gathered in a class of same university, their learning and knowledge dissemination capabilities can be assumed same, which means the time required for students to learn the knowledge is the same; in a similar way students' ability to disseminate knowledge could also be considered the same, that is the individual students have the same ability to spread the knowledge they achieved; while knowledge dissemination in classroom can be seen as a discrete process, which means it's successful to complete knowledge dissemination when an individual student as a recipient can acquire the knowledge from disseminators like teachers or those who have mastered the knowledge and learn how to use the knowledge, otherwise, it 's failed. Here we suppose knowledge is disseminated from disseminator to recipient in large classes with a certain probability, and affects of knowledge itself can be ignored.

Based on the above analysis, the courses teaching in large classes meet six conditions provided in The Complex Network Model of Knowledge Diffusion [4]. According to the conclusions of the study, the basic knowledge dissemination periods are determined, no matter the scale of organization is. i.e. the scale of an organization is independent of spreading cycle[4]. As shown in Fig 2. The timeline represents knowledge dissemination cycle, the dissemination of knowledge in an organization tends to a relatively stable level. Meanwhile in the early dissemination of knowledge dissemination, fewer people acquire new knowledge, but there is a rapidly dissemination of knowledge in the mid-cycle stages, due to a number of individuals to acquire knowledge at this stage to become a new knowledge disseminators. In order to achieve good teaching effects, an effective way of rapid knowledge dissemination should be carried out to allow students master the correlated knowledge of a course in a limited semester. The traditional pyramid-shaped organizational structure should be replaced by an open network structure among which bidirectional communication links exist among individuals within the organization.

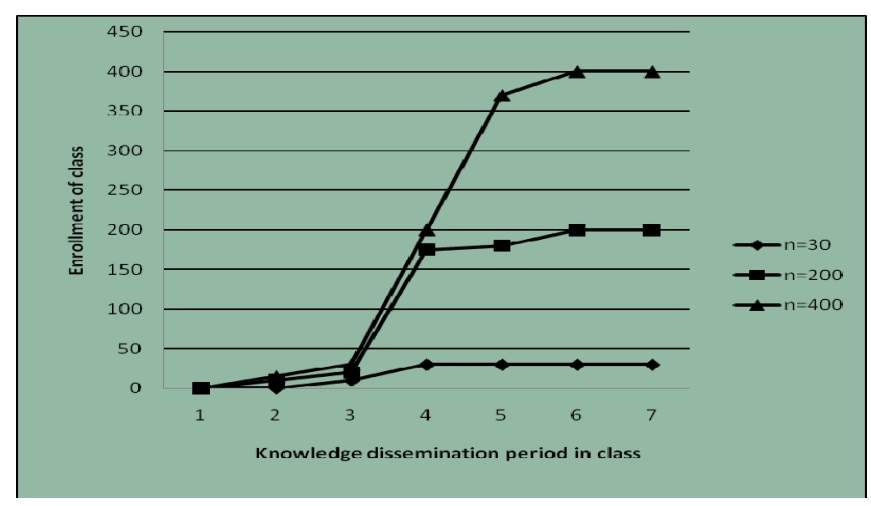

Fig. 2 Knowledge dissemination influences of class scales

\section{COLlaborative KNOWLEDGE BUILDING}

Collaborative knowledge building refers individuals in a particular organization collaborate with each other to participate in some kind of purposeful activity and ultimately form a certain way of thinking or intellectual viewpoint products [5]. Collaborative knowledge building focus on building and improving the knowledge owned by groups as a whole, known as a learning community, form of public community knowledge rather than simply to improve the minds of the content for specific individual. In addition, from the needs of students in terms of access to knowledge, the students have both needs of acquiring academic knowledge (for the understanding of the content of learning ) and social needs ( refer to interact with others and learning activities related to the content, which means students should understand the knowledge acquired at the same time to seek appropriate and effective way to interact with others, to express the cognition of the knowledge. Teachers should promote students' academic and social needs can be achieved. Students as learning individuals should learn actively with the guidance of teachers, that is the essence of teaching. Therefore it's necessary to provide a good platform to ensure an effective communication between teachers and students. Through such platform the pyramidshaped organizational structure exists in large class can be replaced by a new one that provides two-way contact among teacher and students. Thus effective knowledge dissemination can be guaranteed among the learning community in large class. As shown in Fig3.

\section{ApPly EASYClASS INTO TEACHING OF DATABASE APPLICATION}

Database technology is widely used in various industries, so most universities in China offer courses of database application which covers both applications and theories including the theory of relational database systems, database design theory, concurrency control, database security, 
integrity control theory and database management systems concepts, etc.

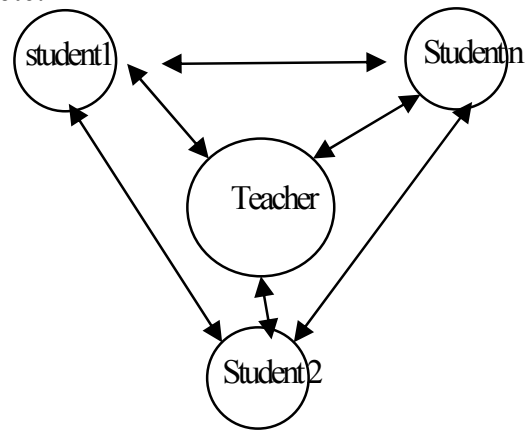

Fig. 3 Knowledge dissemination in large class on CKB

The teaching goal is to equip students with some theoretical basis but also have the ability solve some practical issues. The key to achieve the teaching objectives in limited class hours is to improve the efficiency of teaching and learning activities in the rapid knowledge dissemination cycle, which needs fully mobilization of the students' self-learning ability and effective classroom management expect for emphasis on teaching characteristics and related technologies. The classroom can be seen as a learning organization, teaching is largely the process of interaction between teachers and students and among students. It constantly creates learning contexts and atmosphere which in turn will affect the students' learning.

Easyclass is a newer online learning platform widely used to affiliate class management. It enable teachers easily post assignments, initiate and organize discussions, share teaching materials, carry out test, and evaluate students' participation in activities should be performed online according to their learning behaviour online, through which the foundation of effective communication needed by knowledge dissemination in large class are provided technically. In this paper, the author presents a way to deliver course of database application for a large class over 150 students based on EasyClass to show how to establish an online learning environment under which individuals can communicate easily and collaborate to build the environment to make it benefit all individuals.

\section{A. Large classroom management}

Classroom management refers to a teacher in the teaching activities attract students to actively participate in classroom activities through the coordination of various classroom relationships, so that the classroom environment tends to be optimized state to achieve the intended teaching goals [6]. Attracting students to participate in classroom teaching is the most important part of classroom management. Due to large number of students in a large class, it's much more difficult to manage the classroom for a teacher. It's impossible for the teacher to know each student, so that it is difficult to have an accurate understanding of students' learning behaviour, and make a proper evaluation. To manage large classroom effectively, teaching objective must be clear first, a variety of well-designed teaching tasks require students to complete should also be prepared. Hence the need for a platform through which teachers and students can exchange opinions easily. While students' self-learning ability can be improved, knowledge dissemination through discussions can also be promoted.

Easyclass is a free online course management platform, as its name suggests, with models such as Assignment, Discussion, Gradebook, Classwall and Library teachers can easily create, manage online classroom, post teaching assignments, organize discussions, evaluate students' performance, and students can complete the assignments, discuss with partner students and teachers, share resources and opinions after register in the class on Easyclass with a special course number offered by teacher. Students and teachers can easily enjoy the convenience brought by Easyclass without time-consuming learning to use Easyclass itself. So that teachers can concentrate on teaching tasks design, arrange teaching activities sequentially to attract students to participate in, and guide students to complete the learning process. Teachers first need to register a course in http://www.easyclass.com, and designed teaching tasks can be posted in the form of discussion or assignments for students to complete. See fig 4, Fig 5 .

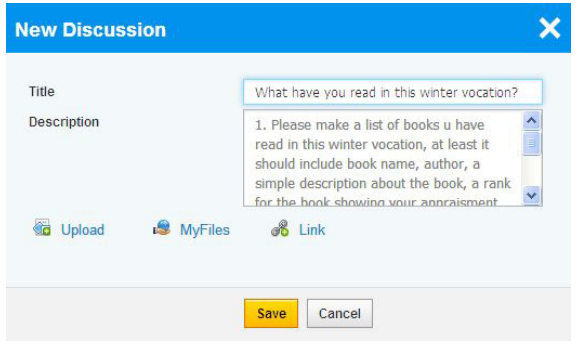

Fig 4 Post new discussion with Easyclass

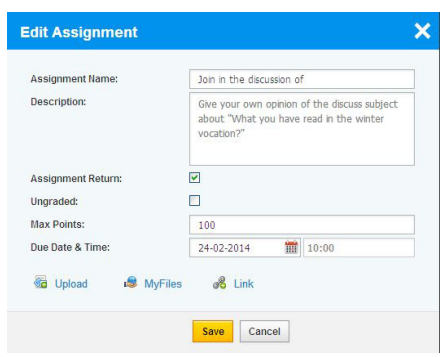

Fig 5 Post new assignment with Easyclass

We designed series of teaching activities for the course of database application. The first one is a discuss about "What have you read in the winter vocation", each student is asked to make a list include at least "book name, author, a simple description of the book, rank for the book", based on the provided information students will be asked to discuss how to store the data to inspire them find proper scheme to store the data respectively, further discusses about "how to access which book is most popular in our class?", "who have read book ****?" can be organized step by step. With the process of discuss we can introduce database theories such as data storage, manipulation, database design, etc. 
Some common issues appeared in the discussion can be published in "Classwall". "Classlibary "offers teachers and students a tool to share and manage resources. Thus teachers and students can collaborate to build a learning community where knowledge can be easily disseminated.

\section{B. Course Assessment in large class}

Course assessment is an effective mean to evaluate teaching effectiveness. It also can motivate students to behave actively in learning process. The purpose of education is not to train students to become expert in examination to obtain high mark, but to have the ability to think independently, identify issues and find proper solutions for the issues. Students' score usually are determined by usual performance with a predetermined weight and final test in most universities of China. This assessment method requires teachers of large classes take a lot of time and effort to statistics student attendance, review students' daily assignments, and record the grades to determine the usual performance of a whole semester. However, as usual performance can be used to activate students to achieve a better learning outcome through their own efforts. Competitive mechanism was introduced in our database application class. Students are divided into groups, with 7-8 students in each group, award points will be recorded for each individual's active participation performance in class, and a group's awarded points is the sum of all group member's awarded points. Each group's award points will be posted online regularly, by which students' learning interest will be activated greatly. Groups model in Easyclass allows teacher to easily manage groups of students. Quizzes model(shown in Fig 6) which includes multiple choice, true/false, or essay quizzes, provides excellent functions for teachers to carry out tests for students.

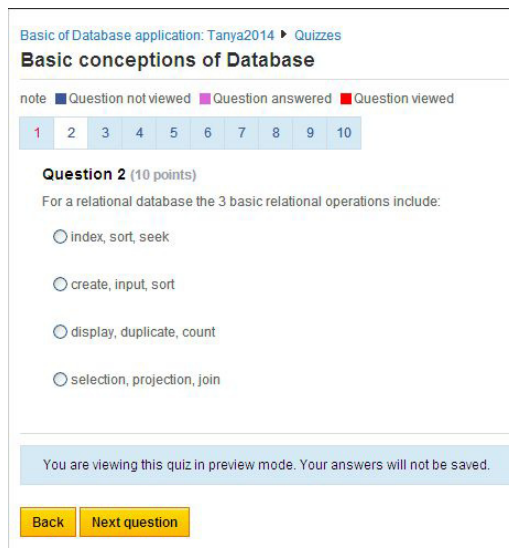

Fig. 6 Use Quizz in Easyclass

Pictures can be included with quiz questions. Instant feedback is available to students at the end of the quiz (except for essay questions) with Easyclass, and quiz scores can be recorded directly in Gradebook of Easyclass. Gradebook model can calculate the final grade for each student instantly according to the assignment scores and quiz scores achieved by students as shown in Fig7.

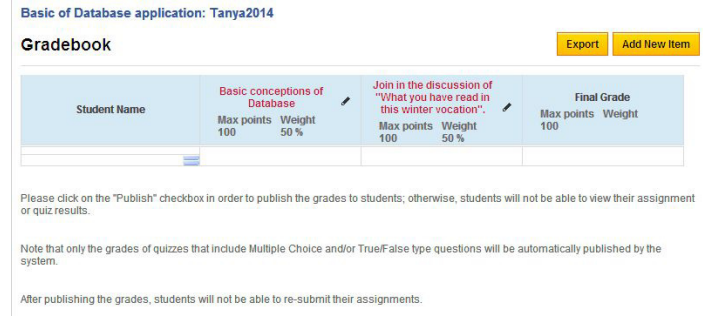

Fig. 7 Manage grade with Gradebook in Easyclass

In the Gradebook the weights of each assignment and quiz can be edited by teachers. The final grade can be a useful measurement of students usual performance.

\section{CONCLUSIONS}

Through the analysis carried out from the perspective of knowledge dissemination within internal organization and Collaborative Knowledge Building, we argued the organization structure of existing large mostly belongs to a pyramid -shaped model, which is not conducive to the spread of knowledge. In order to achieve good teaching effects, the traditional communication way should be changed. An open communication network platform should be employed to promote knowledge dissemination within large classes. Combining teaching practice of database application we found presents Easyclass was a good online teaching platform to change the organizational structure among learning community.

\section{ACKNOWLEDGMENT}

The authors would like to thank peer reviewers for commenting this article. We would like to express our gratitude to all those who helped us during the writing of this thesis. The work was supported by Economic \& Management College of TUST Grant\# JG20130110, Tianjin Education Science Twelfth Five Year Plan projects Grant\# CEYP6005 and\# HE4100, Tianjin Science and Technology Development Strategy Research Program Grant\#13ZLZLZF and Humanities and Social Sciences Projects of Tianjin universities and colleges Grant \#20132155).

\section{REFERENCES}

[1] Chen Yaqing, Liu Shuyan, Zhang Yizhu, Lu Xiaodong. "A case study of Peking University's Semina Education Reform," Educational Research, 2013,11,PP.25-30.

[2] John Kingston. "Choosing a Knowledge Dissemination Approach," Knowledge and Process Management, 2012,Vol.19(3),pp.160-170.

[3] Hu Wanli. "The Complex Network Model of Knowledge Diffusion," OPERATIONS RESEARCH AND MANAGEMENT SCIENCE, Vol. 17,No. 5, pp150-154.

[4] Marlene Scardamalia, "Carl Bereiter. An Architecture for Collaborative Knowledge Building," Computer-Based Learning Environments and Problem Solving. Vol84,1992,PP 41-66.

[5] A. Martinez,Y.Dimitriadis, B.Rubia,E.Gomez, P.de la Fuente. "Combining qualitative evaluation and social network analysis," Computers\&Eduacation 2003(41),pp. 353-368.

[6] Fan-Chuan Tseng,Feng-Yang Kuo. "A study of social participation and knowlege sharing in the teachers," Coumpters\&Eduacation,2004(72),pp.37-47. 